\title{
Synthesis and Neuroprotective Properties of N-Substituted C-Dialkoxyphosphorylated Nitrones
}

\author{
Dorota G. Piotrowska, ${ }^{*}{ }^{\dagger}$ Laura Mediavilla, ${ }^{\ddagger}$ Leticia Cuarental, ${ }^{\ddagger}$ Iwona E. Głowacka, ${ }^{\dagger}$ \\ José Marco-Contelles, ${ }^{\S} \odot$ Dimitra Hadjipavlou-Litina, ${ }^{\|}$Francisco López-Muñoz, ${ }^{\perp, \#}$ \\ and María Jesús Oset-Gasque ${ }^{*, t, \nabla_{\odot}}$
}

${ }^{\dagger}$ Bioorganic Chemistry Laboratory, Faculty of Pharmacy, Medical University of Lodz, Muszyńskiego 1, 90-151 Łódź, Poland

${ }^{\ddagger}$ Department of Biochemistry and Molecular Biology, Faculty of Pharmacy, Complutense University of Madrid, Plaza Ramón y Cajal s/n, Ciudad Universitaria, 28040 Madrid, Spain

${ }^{\S}$ Laboratory of Medicinal Chemistry, Institute of Organic Chemistry (CSIC), Juan de la Cierva 3, 28006 Madrid, Spain

"Department of Pharmaceutical Chemistry, Faculty of Health Sciences, Aristotle University of Thessaloniki, Thessaloniki 54124, Greece

${ }^{\perp}$ Faculty of Health, Camilo José Cela University, Villanueva de la Cañada, 28692 Madrid, Spain

\#Neuropsychopharmacology Unit, “Hospital 12 de Octubre” Research Institute, 28041 Madrid, Spain

${ }^{\nabla}$ Instituto de Investigación en Neuroquímica, Universidad Complutense de Madrid, Ciudad Universitaria, 28040 Madrid, Spain

Supporting Information

ABSTRACT: Herein, we report the synthesis and neuroprotective power of some $\mathrm{N}$-substituted $\mathrm{C}$-(dialkoxy)phosphorylated nitrones $\mathbf{4 a}-\mathbf{g}$, by studying their ability to increase the cell viability, as well as their capacity to reduce necrosis and apoptosis. We have identified (Z)-N-tert-butyl-1(diethoxyphosphoryl)methanimine oxide (4e) as the most potent, nontoxic, and neuroprotective agent, with a high activity against neuronal necrotic cell death, a result that correlates very well with its great capacity for the inhibition of the superoxide production $(72 \%)$, as well as with the inhibition of lipid peroxidation (62\%), and the 5-lipoxygenase activity (45\%) at $100 \mu \mathrm{M}$ concentrations. Thus, nitrone $4 \mathrm{e}$ could be a convenient promising compound for further investigation.

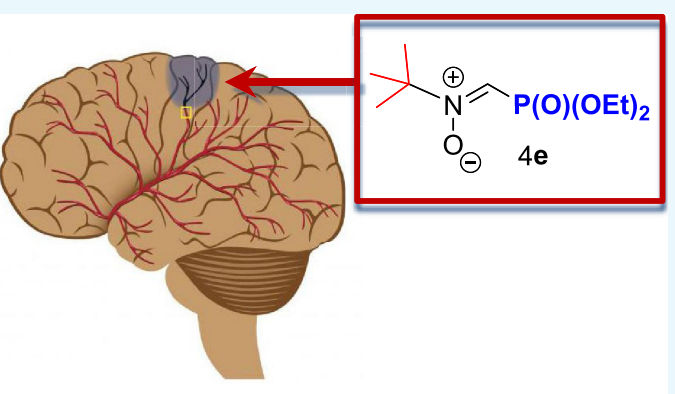

Diethoxyphosphoryl nitrone (DEOPN) $4 \mathrm{e}$ has been identified as the most potent neuroprotective, anti-necrotic agent investigated here, showing capacity to inhibit LP and decrease superoxide levels in neuronal cultures.

\section{INTRODUCTION}

Reactive oxygen species (ROSs) exert their physical functions at low to moderate concentrations, but at high concentrations, they become toxic for the living systems, resulting in oxidative stress (OS). ${ }^{1}$ Oxidative stress (OS) plays a key role in many pathologies, being possibly the most important molecular event occurring before and after ischemic damage. ${ }^{2}$ Aerobic organisms have integrated antioxidant systems, which include enzymatic and nonenzymatic antioxidants that are usually effective in blocking harmful effects of ROS. ${ }^{3}$

In this context, free radical scavengers, such as nitrones like NXY-059 (1) (Figure 1) (Cerovive, AstraZeneca), ${ }^{4,5}$ are efficient neuroprotective agents in experimental ischemia studies. ${ }^{4}$ However, as NXY-059 (1) failed in advanced clinical trials for stroke, the neuroprotection therapy strategy for cerebral ischemia based on antioxidants and nitrone ROS scavenging agents has been critically analyzed and almost discontinued.

In spite of this, the impressive results that we have recently published using novel quinolylnitrones mean that the structure and functional groups incorporated in the nitrone cores have a critical influence on their antioxidant and pharmacological properties $^{7}$ and that there is still place for novelty and originality in this area of medicinal chemistry. On the other hand, as the capability of phosphorylated nitrones DEPMPO $2^{8}$ and 2-(diethoxyphosphoryl)- $\mathrm{N}$-(benzylidene)propan-2amine oxide derivatives $3^{9}$ (Figure 1) to trap various radicals has been well recognized, all of these observations inspired us to study the antioxidant properties of the $\mathrm{N}$-substituted $\mathrm{C}$ dialkoxyphosphorylated nitrones $\mathbf{4 a - g}$, including the (diethoxyphosphoryl)nitrones (DEOPNs) $\mathbf{4 a - e}$ and (dibenzyloxyphosphoryl)nitrones (DBOPNs) 4f,g (Figure 1), and their neuroprotective properties.

\section{RESULTS AND DISCUSSION}

2.1. Chemistry. The phosphorylated nitrones $4 \mathbf{a}-\mathbf{d}$ were synthesized from hydroxymethylphosphonate (5) by Swern oxidation and subsequent reaction with the respective

Received: January 22, 2019

Accepted: April 16, 2019

Published: May 16, 2019 


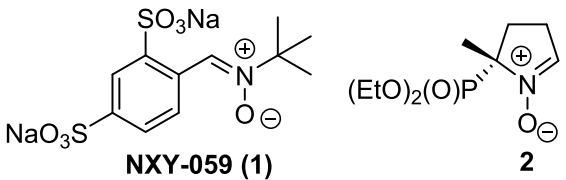<smiles>[R]c1ccc(C=N[N+]([O-])=CC(C)(C)C(C)(C)OCC)cc1</smiles>

3

$\mathrm{R}=\mathrm{OH}, \mathrm{OMe}, \mathrm{NO}_{2}, \mathrm{AcNH}$, $\mathrm{COOH}, \mathrm{COOEt}, \mathrm{CF}_{3}, \mathrm{Me}, \mathrm{Cl}$

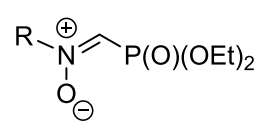

$4 a \mathrm{R}=\mathrm{Me}$

$4 \mathrm{~b} \mathrm{R}=\mathrm{Bn}$

4c $\mathrm{R}=(R)-\mathrm{CH}(\mathrm{Me}) \mathrm{Ph}$

4d $\mathrm{R}=(\mathrm{S})-\mathrm{CH}(\mathrm{Me}) \mathrm{Ph}$

$4 \mathrm{e} R=t-\mathrm{Bu}$

Figure 1. Structures of compounds 1-3 and of the (diethoxyphosphoryl)nitrones (DEOPNs) $4 a-e$ and (dibenzyloxyphosphoryl)nitrones (DBOPNs) $\mathbf{4 f , g}$ investigated in this work.

Scheme 1. Synthesis of Nitrones $4 a-g$

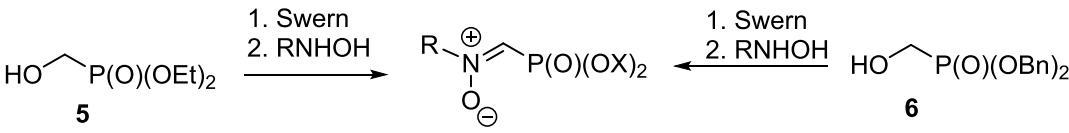

$$
\begin{aligned}
& \text { 4a } \mathrm{R}=\mathrm{Me}, \mathrm{X}=\mathrm{Et} \\
& \text { 4b } \mathrm{R}=\mathrm{Bn}, \mathrm{X}=\mathrm{Et} \\
& \text { 4c } \mathrm{R}=(R)-\mathrm{CH}(\mathrm{Me}) \mathrm{Ph}, \mathrm{X}=\mathrm{Et} \\
& \text { 4d } \mathrm{R}=(S)-\mathrm{CH}(\mathrm{Me}) \mathrm{Ph}, \mathrm{X}=\mathrm{Et} \\
& 4 \mathrm{e} \mathrm{R}=t-\mathrm{Bu}, \mathrm{X}=\mathrm{Et} \\
& 4 f \mathrm{R}=\mathrm{Me}, \mathrm{X}=\mathrm{Bn} \\
& \text { 4g } \mathrm{R}=\mathrm{Bn}, \mathrm{X}=\mathrm{Bn}
\end{aligned}
$$

hydroxylamine $\mathrm{e}^{10-12}$ (Scheme 1 ), whereas nitrones $\mathbf{4 e}$ and $\mathbf{4 f}, \mathbf{g}$ have been synthesized here for the first time in an analogous manner starting from diethyl hydroxymethylphosphonate (5) and dibenzyl hydroxymethylphosphonate (6), respectively (Supporting Information). According to our previous observations, crystalline DEOPN 4a exists as a $Z$ isomer, whereas in chloroform- $d$ as well as in benzene- $d_{6}$ solutions at room temperature, a 15:85 equilibrium mixture of $E / Z$ isomers was noticed $\left({ }^{1} \mathrm{H}\right.$ NMR analysis $) .{ }^{10}$ Similarly, DEOPN $\mathbf{4 b}$ exists as a 14:86 mixture of $E / Z$ isomers. ${ }^{10}$ On the other hand, both $(R)$ and $(S)$-configured DEOPNs $4 \mathrm{c}$ and $\mathbf{4 d}$ in chloroform- $d$ solution form 7:93 mixtures of $E / Z$ isomers. ${ }^{11}$ Nitrones $\mathbf{4 f}$ and $\mathbf{4 g}$ in deuterated chloroform solutions form equilibrium mixtures of $E / Z$ isomers, $10: 90$ and 5:95, respectively, whereas nitrone $4 \mathbf{e}$ exists as only a $Z$ isomer. Surprisingly, all of the phosphorylated nitrones $\mathbf{4 a}-\mathbf{g}$ exist as $Z$ isomers in dimethyl sulfoxide (DMSO) and less than $2 \%$ of $E$-isomers could be detected with a $600 \mathrm{MHz}$ NMR spectrometer.

2.2. Neuroprotective Effect of N-Substituted CDialkoxyphosphorylated Nitrones. Following the usual protocols (see the Supporting Information), we obtained the cell viability and neuroprotection values shown in Table 1 and Figure 2. Based on these results, we conclude that all of the nitrones showed moderate neuroprotective values, in the micromolar range, from 10.62 (4e) to 131.21 (4c). Second, by comparing with the $\mathrm{EC}_{50}$ determined for the standard compounds $\alpha$-phenyl-tert-butyl nitrone (PBN), citicoline (CCh), and $\mathrm{N}$-acetyl-cysteine (NAC), it is clear that most of the nitrones 4 , with the exception of $4 a$ and $4 c$, are more neuroprotective than PBN and CCh but less than NAC.
Among the DEOPNs $4 a-e$, on going from nitrone $4 a(R=$ $\left.\mathrm{Me}, \mathrm{EC}_{50}=98.30 \mu \mathrm{M}\right)$ to nitrones $\mathbf{4 b}$ or $\mathbf{4 e}$, the incorporation of benzyl or t-butyl motifs, respectively, instead of the methyl group, produces strong positive neuroprotective responses, affording the two most neuroprotective agents discovered in this work. Very interestingly, the $\alpha$-substitution on nitrone $\mathbf{4 b}$ by a methyl group significantly decreases the neuroprotection observed for this nitrone, more strongly in the $(R)$-enantiomer $\mathbf{4 c}$ than in the $(S)$-enantiomer $4 \mathbf{d}$. However, nitrones $\mathbf{4 b}$ and $(S)-4 d$ have a lower maximal activity than $(R)-4 \mathbf{c}$, which shows a lower neuroprotection. This is possibly due to the fact that at high concentrations both nitrones are more toxic than $(R)-4 c$. This result is very interesting, showing that the absolute configuration at the stereogenic center has an influence on the neuroprotection, but unfortunately we have no explanation for this fact.

This could also be supported by the results of the effect of these nitrones on the necrotic and apoptotic cell death tests (Figure 3a,b, see below). By comparing DEOPNs $\mathbf{4 a} \mathbf{a}, \mathbf{b}$ with the corresponding DBOPNs $\mathbf{4 f}, \mathbf{g}$, we conclude that nitrone $\mathbf{4 f}$ is 2.2 -fold more potent than nitrone $4 \mathrm{a}(P<0.01)$ but that nitrone $\mathbf{4 b}$ has a neuroprotective potency very similar to that of nitrone $\mathbf{4 g}$ (nonstatistically significant). However, DBOPNs $\mathbf{4 f}, \mathbf{g}$ have a maximal neuroprotective effect higher than those of their corresponding DEOPNs $\mathbf{4 a}, \mathbf{b}$, indicating that the addition of a benzyloxy group, instead of an ethoxy group, affords less toxicity at high concentration.

To shed light on the neuroprotective effects of nitrones $4 a-$ g, the effect of these compounds on necrotic and apoptotic cellular death was measured by monitoring lactate dehydrogen- 
Table 1. Neuroprotective Effects of Nitrones $4 a-g$ on the Cell Viability Decrease Induced by Oxygen-Glucose Deprivation (OGD) and Reperfusion in SHSY5Y Neuroblastoma Cells ${ }^{a}$

\begin{tabular}{|c|c|c|c|c|c|}
\hline Compound & $\begin{array}{l}\text { Structure } \\
\text { (R) }\end{array}$ & $\begin{array}{c}\text { Neuroprotection } \\
\text { EC }_{50} \pm \text { SEM } \\
(\mu \mathrm{M})\end{array}$ & $\begin{array}{l}\text { Maximal } \\
\text { Activity }\end{array}$ & $\begin{array}{c}\mathbf{P}< \\
(\mathbf{P B N})\end{array}$ & $\begin{array}{l}P< \\
(4 \mathrm{e})\end{array}$ \\
\hline $4 a$ & Me & $98.30 \pm 1.94$ & $76.35 \pm 7.05$ & $*$ & $* *$ \\
\hline $4 b$ & Bn & $13.44 \pm 7.95$ & $65.64 \pm 6.17$ & $* *$ & ns \\
\hline $4 c$ & $\begin{array}{c}\text { (R)- } \\
\text { CH(Me)Ph }\end{array}$ & $131.21 \pm 11.27$ & $106.37 \pm 7.13$ & $* *$ & $* *$ \\
\hline 4d & $\begin{array}{c}(\mathrm{S})- \\
\mathrm{CH}(\mathrm{Me}) \mathrm{Ph}\end{array}$ & $30.52 \pm 7.46$ & $52.51 \pm 2.39$ & $* *$ & $* *$ \\
\hline $4 e$ & $t-\mathrm{Bu}$ & $10.62 \pm 3.87$ & $111.75 \pm 11.19$ & $* *$ & - \\
\hline $4 f$ & Me & $44.04 \pm 17.56$ & $102.12 \pm 9.50$ & $*$ & ** \\
\hline $4 \mathrm{~g}$ & Bn & $23.8 \pm 10.70$ & $142.39 \pm 14.05$ & $* *$ & * \\
\hline PBN & - & $81.99 \pm 16.81$ & $52.48 \pm 6.88$ & - & $* *$ \\
\hline $\mathrm{CCh}$ & - & $46.96 \pm 19.46$ & $49.70 \pm 5.40$ & $*$ & $* *$ \\
\hline NAC & - & $1.48 \pm 0.19$ & $103.20 \pm 1.52$ & $* *$ & * \\
\hline
\end{tabular}

${ }^{a}$ Data are given as mean \pm standard error of the mean (SEM). Statistical differences against PBN or compound $4 \mathbf{e}$ were determined by applying a one-way analysis of variance (ANOVA) test. Differences were considered to be statistically significant when $P \leq 0.05$. $\mathrm{EC}_{50}$ 's were calculated from data obtained from three experiments made in triplicate on cells from four different cultures. ns: nonsignificant; *, $P$ $<0.05$; **, $P<0.01$; ***, $P<0.001$; compared with the basal value.

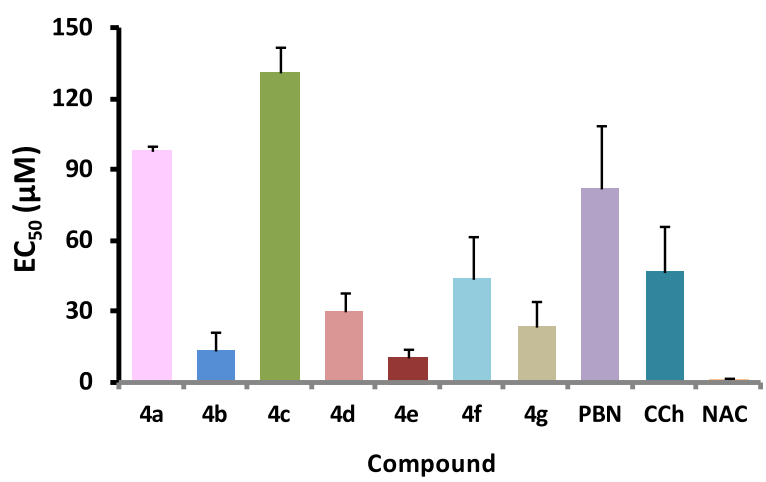

Figure 2. $\mathrm{EC}_{50}$ values of the neuroprotective effect of DEOPNs $4 \mathrm{a}-\mathbf{e}$ and DBOPNs $4 \mathbf{f}, \mathbf{g}$.

ase (LDH) release (necrosis) and caspase-3 activity (apoptosis) from the cultured human neuroblastoma cells.

Results from Figure 3 show that exposure of SHSY5Y cultures to $4 \mathrm{~h}$ OGD (OGD4h) followed by $24 \mathrm{~h}$ reperfusion $(\mathrm{R} 24 \mathrm{~h})$ induced a significant increase in $\mathrm{LDH}$ release $(3.78 \pm$ $0.48 \%$, about 4 -fold of the control values; $P<0.001$, Student's $t$-test) (Figure 3A). These increasing $\mathrm{LDH}$ release values correlate with the loss in cell viability observed under this condition (about 35\%). Exposure of neuroblastoma cell cultures to just $4 \mathrm{~h}$ OGD (OGD4h) also induced a statistically significant increase in $\mathrm{LDH}$ release $(5.48 \pm 0.68 \%$, mean \pm SEM) when compared with control of $4 \mathrm{~h}$ reperfusion (C) $(1.38 \pm 0.20 \%)$, which is about $45 \%$ higher than that induced by IR. This means that, during the OGD treatment, neurons suffered cellular membrane damage, which is partially repaired during reperfusion, parallel to a reduction in cell viability loss of about 30\% during the IR condition. The presence of some nitrones 4 during this period reversed the necrotic death in a concentration-dependent manner (Figure 3A). The neuroprotective effects of nitrones, at concentrations from 1 to 500 $\mu \mathrm{M}$, on necrotic cell death were assayed by adding them at the beginning of the reperfusion period. Their effect was compared with the neuroprotective effect of NAC, from 1 to $500 \mu \mathrm{M}$ doses, showing a decrease in LDH release in a dose-dependent manner, having then a significant neuroprotective effect at concentrations between 10 and $500 \mu \mathrm{M}$ (ranging from 59 to $100 \%$ of maximal reduction) (Figure $3 \mathrm{~A}$ ).

The addition of $10-500 \mu \mathrm{M}$ nitrone $4 \mathrm{e}$ produced a reduction of necrotic cell death, in the same range as NAC (from 55 to $100 \% \mathrm{LDH}$ release inhibition), thus being the most potent neuroprotective nitrone, followed by nitrone $\mathbf{4 a}$ (52-70\% inhibition), indicating that the substitution of Me by the $t$-Bu group increases the neuroprotective and antinecrotic effect. Nitrones $\mathbf{4 b}-\mathbf{d}$ were also able to reduce $\mathrm{LDH}$ release induced by IR in a dose-dependent manner, although nitrone $4 \mathrm{c}$, nitrone $4 \mathrm{~b}$, at $100 \mu \mathrm{M}$ dose, or nitrone $4 \mathrm{~d}$, at 100 and 500 $\mu \mathrm{M}$ concentrations, did not reduce the $\mathrm{LDH}$ release, indicating that, similar to the observed antioxidant and neuroprotective effects, both nitrones are toxic at these concentrations. In general, DEOPNs 4a,b have a neuroprotective effect higher than that of their corresponding DBOPNs, indicating that the addition of a benzyloxy group, instead of the ethoxy, decreases their antinecrotic cell death activity.

The observed high antinecrotic cell death capacity of these nitrones contrasts with their weak capacity to reduce apoptotic cell death. An increase in caspase- 3 activity is correlated with apoptosis. Thus, to know whether these nitrones reduce apoptosis induced by experimental ischemia, the caspase-3 activity was measured.

As shown in Figure 3B, the reduction in caspase-3 activity induced by the nitrones, NAC, and PBN was very small, and only at high concentrations $(100-500 \mu \mathrm{M})$, an antiapoptotic effect was observed. In general, DBOPNs $\mathbf{4 f , g}$ seem to be less antiapoptotic than their analogues DEOPNs, indicating that the incorporation of a benzyloxy group, instead of an ethoxy group, decreases not only their antinecrotic but also their antiapoptotic cell death activity. It is interesting to note that the introduction of a $t$-Bu group in nitrone $4 \mathrm{e}$, the best neuroprotective nitrone in our hands, has an opposite antinecrotic or antiapoptotic effect. Thus, while this chemical modification increases the antinecrotic effect, it decreases its antiapoptotic effect, as shown by comparing these activities between nitrones $\mathbf{4 a}$ and $4 \mathbf{e}$.

To sum up, taken together all of these results of neuroprotection, antinecrotic, and antiapoptotic activities of the nitrones described here, we conclude that the mechanism of their neuroprotective activity might be related to their antinecrotic actions more than their antiapoptotic activity.

2.3. Antioxidant Assays: ROS Production in Cultures of SHSY5Y Human Neuroblastoma Cells. It is well documented that nitrones NXY-059 and PBN have good antioxidant properties. ${ }^{13,14}$ To analyze the antioxidant capacity of nitrones $\mathbf{4}$ and explore whether ROS could be involved in their neuroprotective actions, ex vivo experiments were carried out, following the usual protocols (Supporting Information), to evaluate the effect of these nitrones on ROS production in cultures of SHSY5Y human neuroblastoma cells, under oxygen glucose deprivation (OGD) conditions, using PBN, NAC, and 

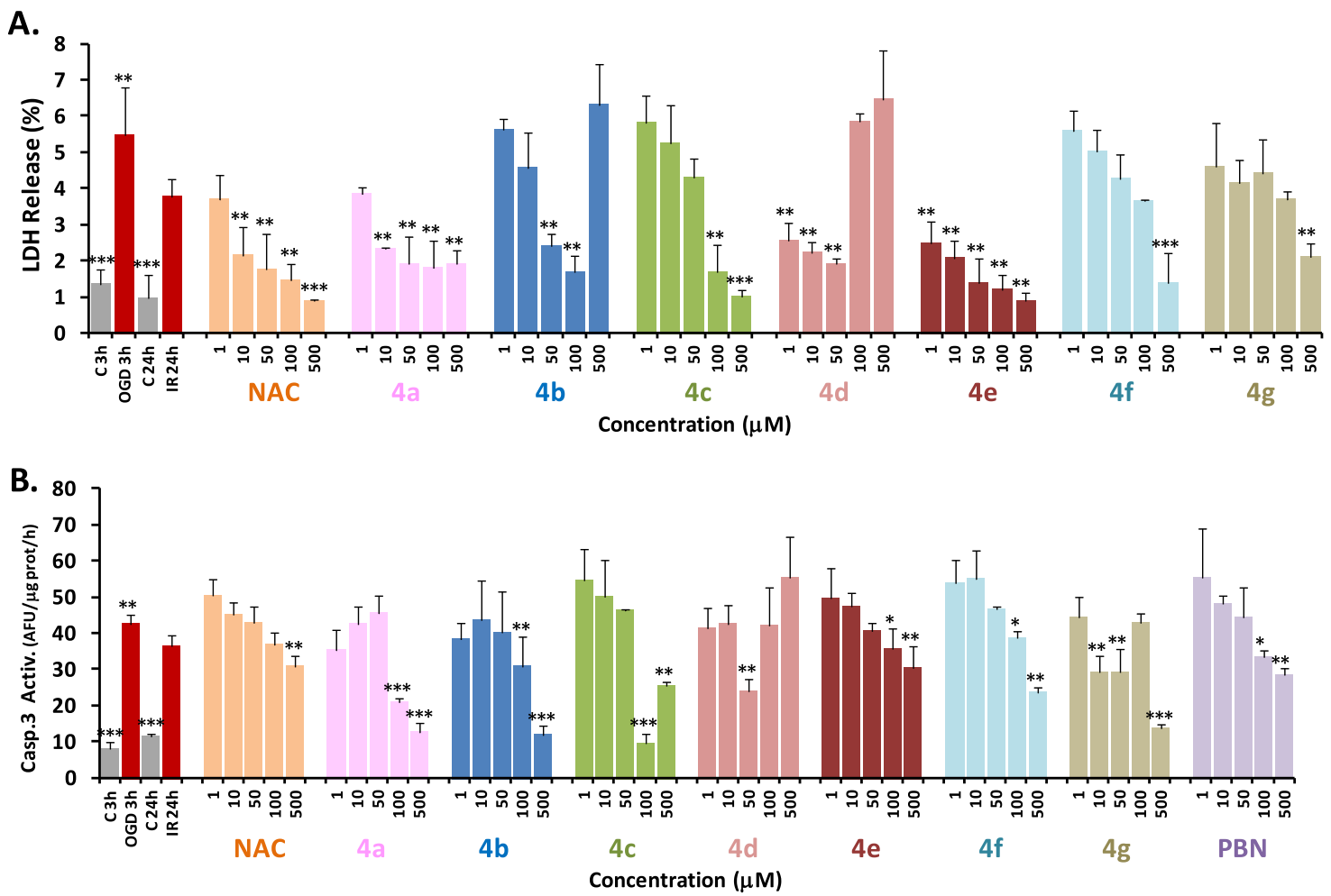

Figure 3. Effect of nitrones on (A) lactate dehydrogenase (LDH) release or (B) caspase-3 activity in SHY5Y human neuroblastoma cell cultures exposed to oxygen-glucose deprivation (OGD). The bar chart shows the percentage of LDH release at $24 \mathrm{~h}$ of recovery after (A) $3 \mathrm{~h}$ OGD or (B) caspase- 3 activity $(\mathrm{AFU} / \mu \mathrm{g}$ protein/h), either untreated $(\mathrm{R} 24 \mathrm{~h})$ or treated with different concentrations $(\mu \mathrm{M})$ of nitrones $4 \mathrm{a}-\mathrm{g}$ or NAC and PBN. The value induced by OGD at $3 \mathrm{~h}$ without the recovery period (OGD3h) is also indicated. LDH release corresponding to R24h cells exposed to 3 $\mathrm{h}$ OGD and $24 \mathrm{~h}$ of reperfusion $(\mathrm{R} 24 \mathrm{~h})(3.78 \pm 0.48 \%)$ was considered as $100 \%$. The values represent the average of three independent experiments (mean \pm SEM) at $* P<0.05$, $* * P<0.01$, and $* * * P<0.001$ vs R24h by one-way analysis of variance followed by Holm-Sidak's posttest, when analysis of variance was significant. Statistical significances above the R24h value are not shown.

$\mathrm{CCh}$ for comparative purposes and sodium nitroprusside (SNP) as the positive control.

To address this issue, we monitored superoxide production by a fluorimetric assay. SHSY5Y neuroblastoma cells in the culture had a basal superoxide production rate of $0.76 \pm 0.072$ $\mathrm{AFU} / \mathrm{min} \times 2 \times 10^{5}$ cells $(n=10$; Figure $4 \mathrm{~A})$. OGD $(3 \mathrm{~h})$ and IR ( $3 \mathrm{~h}$ reperfusion after $3 \mathrm{~h}$ OGD) caused an increase in the rate of $\mathrm{O}_{2}{ }^{--}$production (Figure 4A), reaching values of $1.73 \pm$ 0.18 and $2.59 \pm 0.278 \mathrm{AFU} / \mathrm{min} \times 2 \times 10^{5}$ cells $(n=10)$, respectively, values similar to that obtained for $3 \mathrm{~h}$ of cell treatment with $2 \mathrm{mM}$ SNP. Nitrone $4 \mathrm{e}$ reduced IR-induced superoxide production in a dose-dependent manner, resulting in the $100 \%$ inhibition at $1 \mathrm{mM}$ concentration $(0.82 \pm 0.091$ $\mathrm{AFU} / \mathrm{min} \times 2 \times 105$ cells; $P<0.001$, ANOVA test) (Figure $4 \mathrm{~A}$, inset). Results of Figure $4 \mathrm{~B}$ show that all of the nitrones were able to reduce ROS levels measured by a dihydroethidium (DHE) probe. After reperfusion (IR) for $3 \mathrm{~h}$ and $3 \mathrm{~h}$ under OGD conditions, ROS levels were significantly increased 2.5-fold with respect to the control and also significantly higher than in the OGD conditions alone. Nitrones showed antioxidant power, ranging from a reduction of about $30-35 \%$ for nitrones $4 a$ and $4 c, 60-65 \%$ for nitrones 4d and $4 \mathrm{f}(0.1 \mathrm{mM}$ concentrations $)$, and $40-45 \%$ for nitrones $4 \mathbf{a}, \mathbf{b}, \mathbf{d}$ or $70-80 \%$ for the most potent antioxidant nitrones $4 \mathrm{e}$ and $\mathbf{4 f}$ (at $1 \mathrm{mM}$ concentration). In the case of nitrones $\mathbf{4 b}$ and 4d, an inverse relationship exists between the nitrone concentration and antioxidant activity, indicating thus a possible toxic effect at concentrations higher than $1 \mathrm{mM}$. These results confirm that the antioxidant power of the nitrones tested here translates into their neuroprotective activity (see below). Interestingly, nitrone $\mathbf{4 f}$ is one of the most potent antioxidant nitrones in the ex vivo analysis, especially at a high, $1 \mathrm{mM}$, concentration, showing ROS (\%) reduced values higher than those observed for PBN, NAC, and CCh (Figure 4B).

We observed that, among DEOPNs $\mathbf{4 a}-\mathbf{e}$, nitrones $\mathbf{4 d}$ and $4 \mathbf{e}$ are the most potent antioxidants. The incorporation of benzyl or t-butyl motifs, instead of the methyl group, seems to increase the antioxidant capacity of these nitrones, and the $\alpha$ substitution on nitrone $\mathbf{4 b}$ by a methyl group significantly increases its antioxidant capacity, more strongly in the resulting $(R)$-enantiomer $4 \mathrm{c}$ than in the $(S)$-enantiomer $4 \mathrm{~d}$. However, both nitrones $\mathbf{4 b}$ and the $(S)$-enantiomer $4 \mathbf{d}$ show less antioxidant activity at $1 \mathrm{mM}$ than at $0.1 \mathrm{mM}$ concentrations, which is possibly due to the fact that at high concentrations both nitrones are more toxic than $(R)$-enantiomer nitrone $4 \mathrm{c}$. By comparing DEOPNs $\mathbf{4 a}$ and $\mathbf{4 b}$ with the corresponding DBOPNs $\mathbf{4 f}$ and $\mathbf{4 g}$, we conclude that nitrone $\mathbf{4 f}$ is 2 -fold more potent than nitrone $4 \mathrm{a}(\mathrm{R}=\mathrm{Me})(P<0.01)$ but that nitrone $\mathbf{4 b}$ has a neuroprotective potency very similar to that of nitrone $\mathbf{4 g}(\mathrm{R}=\mathrm{Bn})$ (nonstatistically significant).

Very interestingly, the most potent neuroprotective nitrone 4e shows high values for the inhibition of the lipid peroxidation (LP) (62\%), inhibition of the 5-lipoxygenase (LOX) (45\%), and lipophilicity (Clog $P=2.04)$ (Table 2). These results are in good agreement with its capacity to inhibit superoxide production shown in the ex vivo experiments (about $100 \%$ at $1 \mathrm{mM}$; Figure $4 \mathrm{~A}, \mathrm{~B}$ ). Thus, the antioxidant 
A.

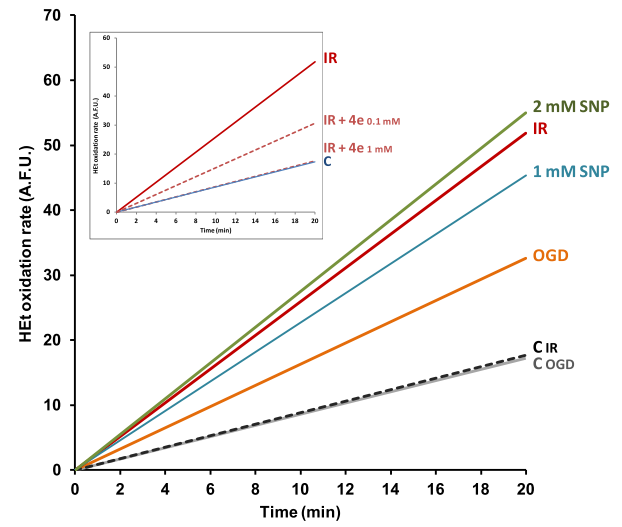

B.

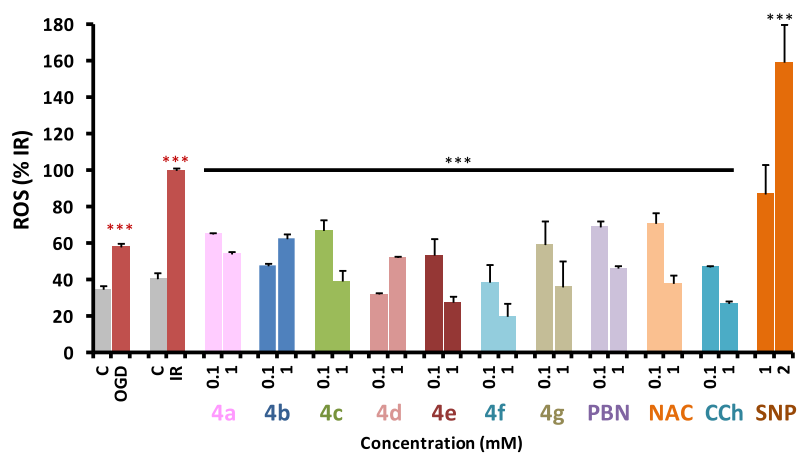

Figure 4. Inhibitory effects of nitrones 4 on ROS (superoxide) production in SHSY5Y human neuroblastoma cell cultures exposed to OGD 3 and $3 \mathrm{~h}$ reperfusion (IR). (A) Rate of experimental ischemia and reperfusion-induced superoxide production. ROS production was determined as indicated in Methods. The slopes of the lines fitting the fluorescence intensity changes (an index of the rate of superoxide production) were individually calculated and averaged. The mean slope values were used to generate a theoretical line using the following equation: $y=a x$. The figure represents the generated lines for superoxide production in untreated cells and in the presence of OGD, IR, and SNP as a positive control. The inset represents the effect of 0.1 and $1 \mathrm{mM}$ nitrone $4 \mathrm{e}$ on superoxide production induced by experimental ischemia (OGD + reperfusion; IR). (B) Effect of nitrones 4 on the ROS levels induced by IR. The bars show the percentage of ROS obtained by the IR treatment in the absence and presence of the indicated concentrations of nitrones, PBN, NAC, and $\mathrm{CCh}$. The data represent the mean \pm SEM of three determinations, each performed in triplicate $(n=9)$. The statistics compare the effect of the OGD or IR over their respective controls at 3 and $3+3 \mathrm{~h}$, respectively $(*$ red), or the effect of the different compounds on the IR condition (*black) to ***P $<0.001$ (one-way ANOVA, followed by Holm-Sidak analysis as a post hoc test). SNP (1-2 mM) was used as a positive control of ROS formation.

Table 2. Clog $P$ and in Vitro Inhibition of LOX and LP Antioxidant Activity of Nitrone 4e and the Standards ${ }^{a}$

$\begin{array}{lccc}\text { compounds } & \mathrm{Clog} P & \mathrm{LOX}^{a}(\%) & \mathrm{LP}^{a}(\%) \\ 4 \mathrm{e} & 2.04 & 45 & 62 \\ \text { NDGA } & - & 91 & - \\ \text { Trolox } & - & - & 88\end{array}$

${ }^{a}$ Nitrone and standards tested at $100 \mu \mathrm{M}$; values are means \pm standard deviation of three or four different determinations. - , no activity under the experimental conditions. Means within each column differ significantly $(P<0.05)$.

properties of these nitrones could be strongly involved in their neuroprotective effects.

\section{CONCLUSIONS}

We report herein the synthesis and neuroprotective properties of some $\mathrm{N}$-substituted $\mathrm{C}$-dialkoxyphosphorylated nitrones 4, easily available in good yields from commercial starting materials. Regarding the neuroprotection analysis, DEOPNs $t$-butyl nitrone $4 \mathrm{~b}$ and benzyl nitrone $4 \mathrm{e}$ have been identified as good neuroprotective nitrones, although in the case of nitrone $4 \mathrm{~b}$, no clear trends have been observed to correlate these results with its antioxidant capacity. The replacement of a methyl group with a $t$-butyl or benzyl group improves the neuroprotective power of the corresponding nitrone. Similarly, the replacement of the benzyl with a methyl group reduces the neuroprotective capacity, resulting in less-potent nitrones $4 \mathrm{c}$ and $4 \mathrm{~d}$, where we have observed that the $(S)$-enantiomer is 4.2-fold more potent than the $(R)$-enantiomer. To sum up, DEOPN 4e has been identified as the most potent neuroprotective, antinecrotic agent investigated here, showing the capacity to inhibit LP and decrease superoxide levels in neuronal cultures, and consequently deserves further investigation. The etiology and origin of stroke, as a complex and multifactorial disease, is unknown. However, as the oxidative stress is thought to play a key role, among other factors, we have tried to explain the observed neuroprotective effect by nitrone $4 \mathrm{e}$ on these grounds but without excluding other factors and mechanisms being involved.

\section{EXPERIMENTAL SECTION}

4.1. Chemistry: General Methods. ${ }^{1} \mathrm{H}$ NMR spectra were recorded in $\mathrm{CDCl}_{3}$ on the following spectrometers: Varian Mercury-300 and Bruker Avance III (600 MHz) with tetramethylsilane as the internal standard. ${ }^{13} \mathrm{C}$ NMR spectra were recorded for $\mathrm{CDCl}_{3}$ solution on the Varian Mercur-300 machine at $75.5 \mathrm{MHz}$, whereas for DMSO solution on Bruker Avance III at $151.0 \mathrm{MHz}$. IR spectra were recorded on an Infinity MI-60 FT-IR spectrometer. Melting points were determined on Boetius apparatus and were uncorrected. Elemental analyses were carried out on a PerkinElmer PE 2400 CHNS analyzer. The following adsorbents were used: column chromatography, Merck silica gel 60 (70-230 mesh); analytical TLC, Merck TLC plastic sheets silica gel 60 F254.

4.2. General Method for the Synthesis of Nitrones. To a stirred solution of oxalyl chloride $(0.210 \mathrm{~mL}, 2.48 \mathrm{mmol})$ in $\mathrm{CH}_{2} \mathrm{Cl}_{2}(5 \mathrm{~mL})$ under an argon atmosphere, DMSO $(0.360$ $\mathrm{mL}, 5.15 \mathrm{mmol})$ dissolved in $\mathrm{CH}_{2} \mathrm{Cl}_{2}(1.5 \mathrm{~mL})$ was added dropwise at $-60{ }^{\circ} \mathrm{C}$. After $30 \mathrm{~min}$, a solution of the appropriate dialkoxy hydroxymethylphosphonate 5 or $\mathbf{6}(2.0$ $\mathrm{mmol})$ in $\mathrm{CH}_{2} \mathrm{Cl}_{2}(2 \mathrm{~mL})$ was added followed by triethylamine $(0.850 \mathrm{~mL}, 6.00 \mathrm{mmol})$ and the respective alkylhydroxylamine $(2.0 \mathrm{mmol})$. The cooling bath was removed, and saturated aqueous $\mathrm{NaHCO}_{3}(10 \mathrm{~mL})$ was added when the temperature of the reaction mixture reached $0{ }^{\circ} \mathrm{C}$. The aqueous layer was extracted with $\mathrm{CH}_{2} \mathrm{Cl}_{2}(3 \times 5 \mathrm{~mL})$, and the organic phases combined were washed with brine, dried $\left(\mathrm{MgSO}_{4}\right)$, and concentrated to yield the crude nitrone 4 , which was purified by column chromatography using a chloroform- $-\mathrm{MeOH}$ mixture (50:1). More details about these methods are briefly described in the Supporting Information.

4.3. Antioxidant "in Vitro" Assays. In vitro inhibition of linoleic acid peroxidation and soybean-lipoxygenase was evaluated spectrophotometrically as reported previously. ${ }^{15}$ These methods are briefly described in the Supporting Information. 
4.4. Neuroprotection Assays. 4.4.1. Neuroblastoma Cell Cultures. The human neuroblastoma cell line SHSY5Y was cultured in Dulbecco's modified Eagle's medium: Ham's F12 medium as described in ref 16 . For assays, SHSY5Y cells were subcultured in 96- or 48-well plates at a seeding density of $(0.50-1)$ or $(2-2.5) \times 10^{5}$ cells per well, respectively. When the SHSY5Y cells reached $80 \%$ confluence, the medium was replaced with fresh medium containing $0.01 \mu \mathrm{M}$ to $10 \mathrm{mM}$ compound concentrations or PBS in the controls, as indicated in each assay.

4.4.2. Neuroblastoma Cell Culture Exposure to OxygenGlucose Deprivation (OGD). Neuroblastoma cell cultures were exposed to OGD so as to induce cellular damage (experimental ischemia). Cultured cells were washed and placed in glucose-free Dulbecco's medium and maintained in an anaerobic chamber containing a gas mixture of $95 \% \mathrm{~N}_{2} / 5 \%$ $\mathrm{CO}_{2}$ and humidified at $37^{\circ} \mathrm{C}$, as described in ref 17 . Cells were exposed to OGD for a period of 3-4 h (OGD4h), as indicated. Then, the culture medium was replaced with oxygenated serum-free medium and cells were placed and maintained in the normoxic incubator for $24 \mathrm{~h}$ for recovery (R24h). Nitrones were analyzed independently three to five times with different batches of cultures, and each experiment was run in triplicate.

4.4.3. Assessment of Cell Viability. Measurements of cell viability in human SHSY5Y neuroblastoma cells (about (0.751) $\times 10^{5}$ cells/well) were carried out in 96-well culture plates by the XTT methods, as described in ref $17 .^{17}$

4.4.4. Measurement of LDH Activity. For these assays, cultured neuroblastoma cells grown in 96-well culture dishes at a density of $1.5 \times 10^{5}$ cells/well were used. LDH activity was measured as the rate of decrease of the absorbance at $340 \mathrm{~nm}$, resulting from the oxidation of $\mathrm{NADH}$ to $\mathrm{NAD}^{+}$as described. ${ }^{17}$ Data are given as the percentage of $\mathrm{LDH}$ release with respect to the total $\mathrm{LDH}$ content ( $\mathrm{LDH}$ in the culture medium and LDH inside the cells).

4.4.5. Analysis of Caspase-3 Activity. For these assays, cultured neuroblastoma cells grown in 48-well culture dishes, at a density of $2.5 \times 10^{5}$ cells/well, were used. After OGD treatment, cells were treated with different nitrones or indicated positive controls at $1-500 \mu \mathrm{M}$ concentrations and subjected to $24 \mathrm{~h}$ reperfusion. Attached cells were lysed at $4{ }^{\circ} \mathrm{C}$ in a lysis medium containing $5 \mathrm{mM}$ Tris $/ \mathrm{HCl}(\mathrm{pH} \mathrm{8.0)}, 20$ $\mathrm{mM}$ ethylenediaminetetraacetic acid, and $0.5 \%$ Triton X-100 and centrifuged at $13000 \mathrm{~g}$ for $10 \mathrm{~min}$. The activity of caspase3 was measured using the fluorogenic substrate peptide DEVD-amc (66081; BD Biosciences PharMingen), as described in refs 17, 18. Proteins were measured by the Bradford assay. Results were expressed as arbitrary fluorescence units $[(\mathrm{AFU}) / \mu \mathrm{g}$ protein $/ \mathrm{h}]$.

4.4.6. Measurement of ROS Formation. SHSY5Y human neuroblastoma cells $\left(2 \times 10^{5}\right.$ cells/well $)$ were exposed to OGD for a period of $3 \mathrm{~h}$ (OGD3h). At the end of the OGD period, the culture medium was replaced with oxygenated Dulbecco's modified Eagle's medium containing glucose and $10 \%$ fetal calf serum. Cells were treated in the absence (controls) or presence of indicated concentrations of nitrones or different known neuroprotective agents and maintained at $37^{\circ} \mathrm{C}$ in a normoxic incubator for $3 \mathrm{~h}$ for recovery. At the end of this period, $20 \mu \mathrm{M}$ DHE (HEt; Molecular Probes) was added and fluorescence was recorded every $15-30 \mathrm{~s}$ during a $15 \mathrm{~min}$ period, using an excitation filter of $535 \mathrm{~nm}$ and an emission filter of $635 \mathrm{~nm}$ in a spectrofluorimeter (Bio-Tek FL 600) as previously described. ${ }^{18,19}$ Linear regression of fluorescence data [expressed as arbitrary fluorescence units (AFU)] was calculated for each condition, and the slopes $(a)$ of the best fitting lines $(y=a x)$ were considered as an index of $\mathrm{O}_{2}^{\bullet-}$ production. SNP was used as a positive control of superoxide production. ${ }^{19}$

4.5. Statistical Analysis. Data were expressed as mean \pm SEM of results obtained from at least three independent experiments from different cultures, each of which was performed in triplicate. Statistical comparisons between the different experimental conditions were performed using oneway analysis of variance (ANOVA), followed by Holm-Sidak's post-test when the analysis of variance was significant. A $P$ value $<0.05$ was considered statistically significant. Fit curves for $\mathrm{EC}_{50}$ determinations were performed according to the program of SigmaPlot v.11 (Systat Software INC., 2012).

\section{ASSOCIATED CONTENT}

\section{Supporting Information}

The Supporting Information is available free of charge on the ACS Publications website at DOI: 10.1021/acsomega.9b00189.

Synthesis of nitrones $\mathbf{4 a}-\mathbf{g}$ and antioxidant activity in vitro test methods; inhibition of linoleic acid peroxidation; in vitro inhibition of soybean-lipoxygenase; estimation of lipophilicity as Clog P (PDF)

\section{AUTHOR INFORMATION}

\section{Corresponding Authors}

*E-mail: dorota.piotrowska@umed.lodz.pl (D.G.P.).

*E-mail: mjoset@ucm.es (M.J.O.-G.).

ORCID

José Marco-Contelles: 0000-0003-0690-0328

María Jesús Oset-Gasque: 0000-0002-7223-0222

Notes

The authors declare no competing financial interest.

\section{ACKNOWLEDGMENTS}

The synthetic part of the project was supported by the National Science Centre (grant UMO-2015/17/B/ST5/ 00076). D.H.-L. gratefully acknowledges Dr A. Leo and Biobyte Corp., 201 West 4th Street, Suite 204, Claremont, CA 91711, for free access to the C-QSAR program. J.M.-C. and M.J.O.-G. thank MINECO (Government of Spain) (SAF201565586-R) and Universidad Camilo José Cela (NitroStroke project, 2015-12) for support.

\section{REFERENCES}

(1) Lutskii, M. A.; Zemskov, A. M.; Razuvaeva, V. V.; Lushnikova, Y. P.; Karpova, O. Y. Oxidative stress as an indicator of metabolic impairments in the pathogenesis of cerebral stroke. Neurosci. Behav. Physiol. 2018, 48, 64-68.

(2) Li, P.; Stetler, R. A.; Leak, R. K.; Shi, Y.; Li, Y.; Yu, W.; Bennett, M. V. L.; Chen, J. Oxidative stress and DNA damage after cerebral ischemia: Potential therapeutic targets to repair the genome and improve stroke recovery. Neuropharmacology 2018, 134 B, 208-217.

(3) Hensley, K.; Robinson, K. A.; Gabbita, S. P.; Salsman, S.; Floyd, R. A. Reactive oxygen species, cell signaling, and cell injury. Free Radical Biol. Med. 2000, 28, 1456-1462.

(4) Floyd, R. A.; Kopke, R. D.; Choi, C. H.; Foster, S. B.; Doblas, S.; Towner, R. A. Nitrones as therapeutics. Free Radical Biol. Med. 2008, 45, 1361-1374.

(5) Edenius, C.; Strid, S.; Borgå, O.; Breitholtz-Emanuelsson, A.; Vallén, K. L.; Fransson, B. Pharmacokinetics of NXY-059, a nitrone- 
based free radical trapping agent, in healthy young and elderly subjects. J. Stroke Cerebrovasc. Dis. 2002, 11, 34-42.

(6) Diener, H. C.; Lees, K. R.; Lyden, P.; Grotta, J.; Dávalos, A.; Davis, S. M.; Shuaib, A.; Ashwood, T.; Wasiewski, W.; Alderfer, V.; Hårdemark, H. G.; Rodichok, L. NXY-059 for the treatment of acute stroke: pooled analysis of the SAINT I and II trials. Stroke 2008, 39, 1751-1758.

(7) Chioua, M.; Martinez-Alonso, E.; Gonzalo-Gobernado, R.; Ayuso, M. I.; Escobar-Peso, A.; Infantes, L.; Hadjipavlou-Litina, D.; Montoya, J. J.; Montaner, J.; Alcazar, A.; Marco-Contelles, J. New Quinolylnitrones for Stroke Therapy: Antioxidant and Neuroprotective (Z)-N-tert-Butyl-1-(2-chloro-6-methoxyquinolin-3-yl) methanimine Oxide as a New Lead- Compound for Ischemic Stroke Treatment. J. Med. Chem. 2019, 62, 2184-2201.

(8) Hardy, M.; Chalier, F.; Finet, J. P.; Rockenbauer, A.; Tordo, P. Diastereoselective synthesis and ESR study of 4-phenylDEPMPO spin traps. J. Org. Chem. 2005, 70, 2135-2142.

(9) Cassien, M.; Petrocchi, C.; Thetiot-Lauren, S.; Robin, M.; Ricquebourg, E.; Kandouli, C.; Asteian, A.; Rockenbauer, A.; Mercier, A.; Culcasi, M.; Pietri, S. On the vasoprotective mechanisms underlying novel $\beta$-phosphorylated nitrones: Focus on free radical characterization, scavenging and NO-donation in a biological model of oxidative stress. Eur. J. Med. Chem. 2016, 119, 197-217.

(10) Piotrowska, D. G. N-Substituted C-diethoxyphosphorylated nitrones as useful synthons for the synthesis of $\alpha$-aminophosphonates. Tetrahedron Lett. 2006, 47, 5363-5366.

(11) Piotrowska, D. G.; Glowacka, I. E. Enantiomerically pure phosphonate analogues of cis- and trans-4-hydroxyprolines. Tetrahedron: Asymmetry 2007, 18, 1351-1363.

(12) Piotrowska, D. G. Stereochemistry of substituted isoxazolidines derived from N-methyl C-diethoxyphosphorylated nitrone. Tetrahedron 2006, 62, 12306-12317.

(13) Oliveira, C.; Benfeito, S.; Fernandes, C.; Cagide, F.; Silva, T.; Borges, F. NO and HNO donors, nitrones, and nitroxides: Past, present, and future. Med. Res. Rev. 2018, 38, 1159-1187.

(14) Arce, C.; Dìa-Castroverde, S.; Canales, M. J.; Marco-Contelles, J.; Samadi, A.; Oset-Gasque, M. J.; González, M. P. Drugs for stroke: action of nitrone (Z)-N-(2-bromo-5-hydroxy-4-methoxybenzylidene)2-methylpropan-2-amine oxide on rat cortical neurons in culture subjected to oxygen-glucose-deprivation. Eur. J. Med. Chem. 2012, 55, 475-479.

(15) Chioua, M.; Sucunza, D.; Soriano, E.; Hadjipavlou-Litina, D.; Alcázar, A.; Ayuso, L. I.; Oset-Gasque, M. J.; González, M. P.; Monjas, L.; Rodríguez-Franco, M. I.; Marco-Contelles, J.; Samadi, A. $\alpha$-Aryl$\mathrm{N}$-alkyl nitrones, as potential agents for stroke treatment: synthesis, theoretical calculations, antioxidant, anti-inflammatory, neuroprotective and brain-blood barrier permeability properties. J. Med. Chem. 2012, 55, 153-168.

(16) García-Font, N.; Hayour, H.; Belfaitah, A.; Pedraz, J.; Moraleda, I.; Iriepa, I.; Bouraiou, A. Q.; Chioua, M.; Marco-Contelles, J.; OsetGasque, M. J. Potent anticholinesterasic and neuroprotective pyranotacrines as inhibitors of beta-amyloid aggregation, oxidative stress and tau-phosphorylation for Alzheimer's disease. Eur. J. Med. Chem. 2016, 118, 178-192.

(17) Jiménez-Almarza, A.; Diez-Iriepa, D.; Chioua, M.; Chamorro, B.; Iriepa, I.; Martínez-Murillo, R.; Hadjipavlou-Litina, D.; OsetGasque, M. J.; Marco-Contelles, J. Synthesis, neuroprotective and antioxidant capacity of PBN-related indanonitrones. Bioorg. Chem. 2019, 86, 445-451.

(18) Vicente, S.; Pérez-Rodríguez, R.; Oliván, A. M.; Martínez Palacián, A.; González, M. P.; Oset-Gasque, M. J. Nitric oxide and peroxynitrite induce cellular death in bovine chromaffin cells: Evidence for a mixed necrotic and apoptotic mechanism with caspases activation. J. Neurosci. Res. 2006, 84, 78-96.

(19) Jordán, J.; Galindo, M. F.; Calvo, S.; González-García, C.; Ceña, $\mathrm{V}$. Veratridine induces apoptotic death in bovine chromaffin cells through superoxide production. Br. J. Pharmacol. 2000, 130, 14961504 . 